PAPER

\title{
Prevalence and characteristics of patients in a vegetative state in Dutch nursing homes
}

\author{
J C M Lavrijsen, J S G van den Bosch, R T C M Koopmans, C van Weel
}

J Neurol Neurosurg Psychiatry 2005;76:1420-1424. doi: 10.1136/jnnp.2004.058198

See end of article for authors' affiliations

\section{Correspondence to:}

J Lavrijsen, Radboud University Nijmegen Medical Centre, PO Box 9101, (229 VPHG), 6500 HB Niimegen, the Netherlands; i.lavriisen@ vphg.umon.nl

Received

10 November 2004

Revised version received

28 January 2005

Accepted 6 February 2005

\begin{abstract}
Objectives: To establish the prevalence of vegetative state in Dutch nursing homes, describe the patient characteristics, and highlight the possible influence of medical decisions at the end of life.

Design: A cross-sectional survey. The vegetative state was defined according to the Multi Society Task Force on PVS. All Dutch nursing homes were approached to provide data on patients in a vegetative state. In cases of doubt, the researcher discussed the diagnosis with the patient's physician and, if necessary, examined the patient. Information on patients in a vegetative state in care between 2000 and September 2003 and end of life decisions for them were also recorded.

Results: All nursing homes and physicians participated. After assessment of 12 doubtful patients, 32 met the criteria of vegetative state lasting longer than one month, a prevalence of $2 / 1000000$. Of these, 30 patients' data were analysed: age 9-90 years; $73 \%$ female; duration of vegetative state 2 months -20 years (26 surviving $>1$ year, $13>5$ years). Stroke was the commonest cause. Between 2000 and September 2003, there were 76 patients in a vegetative state in care of whom 34 died of complications and nine after withdrawal of artificial nutrition and hydration.

Conclusions: The prevalence of vegetative state in Dutch nursing homes has been established for the first time. The figures are lower than suggested in the literature. The study included a heterogeneous group of patients, of which a substantial number survived for many years. The results cannot be explained by a policy of systematically withdrawing artificial nutrition and hydration.
\end{abstract}

$\mathrm{P}$ atients who do not regain consciousness after a comatose phase following acute brain damage can end up in a vegetative state, showing a sleep-wake cycle without any signs of awareness. ${ }^{1}$ Their fate has been described as a "fate worse than death". ${ }^{2}$ Over the past 10 years, international working groups have provided more clarity on terminology, diagnosis, prognosis, and the care of these patients. ${ }^{4-6}$ Required care is intensive and complex, and the medico-ethical dilemmas in treatment decisions increase as the chances of recovery become doubtful. ${ }^{7}$ Recovery from a vegetative state becomes unlikely once this state persists for some time-that is, longer than 12 months after trauma or three to six months in the case of non-traumatic brain damage. ${ }^{589}$ In such a context, single cases may attract the attention of the media worldwide. ${ }^{10}$

Surprisingly, little is known about the exact number of patients in a vegetative state or their medical history in long term care. ${ }^{11}$ Confusion about terminology and a lack of accepted diagnostic and inclusion criteria are contributing factors, ${ }^{6}$ and this is reflected in the variation and wide range of reported estimates of prevalence-from 5 to 140 cases per million people. ${ }^{46}{ }^{11}$ However, with the current background knowledge it is possible to conduct accurate research on the prevalence. This is important to assess the implications of the problem from a realistic perspective and to plan specialised care facilities and develop better care.

The complex long term care provided by nursing homes makes these institutions most suitable for a survey of patients in a vegetative state. However, the available data are rather limited, particularly with regard to nationwide populations of nursing home patients in a vegetative state after acute brain damage. A few studies have included a (local) hospital population, ${ }^{12}{ }^{13}$ others have included patients with developmental disorders or regressive-degenerative disease. ${ }^{14} 15$
The special circumstances in the Netherlands provide an excellent opportunity for a prevalence study as there are more than 330 nursing homes for a population of 16.2 million people and these are well distributed throughout the country. ${ }^{16}{ }^{17}$ Professional care is standardised and provided via multidisciplinary teams, which are led by specialist nursing home physicians. ${ }^{18}$ A multidisciplinary guideline for the diagnosis of the vegetative state has recently been published. ${ }^{19}$ This specialised care is necessary to deal with the complex dilemmas of the vegetative state, including decisions about the withdrawal of treatment and artificial nutrition and hydration (ANH). ${ }^{90}$

Therefore the present study aimed to investigate the prevalence of patients in a vegetative state after acute brain damage in all nursing homes in the Netherlands and to describe the main characteristics of these patients. We also aimed to highlight the possible influence of medical decisions at the end of life in the years before the study.

\section{METHODS}

We conducted a cross-sectional survey with a three step design (see fig 1 Results) of the number of patients in a vegetative state in all Dutch nursing homes.

In step 1 , we sent a letter to all the nursing home physicians of all nursing homes and long term nursing care facilities $(n=380)$ in the Netherlands informing them about the study. The first author (JL) then contacted them by telephone for an inventory of all probable cases of vegetative state in care in September 2003. The vegetative state was defined according to the criteria of the Multi Society Task Force on PVS and an article explaining this, based on a literature study and an expert meeting, was also sent with the letter. ${ }^{49}$ We directed our survey at patients in a vegetative state for at least one month after acute brain damage. Patients with degenerative disease as a cause (for 


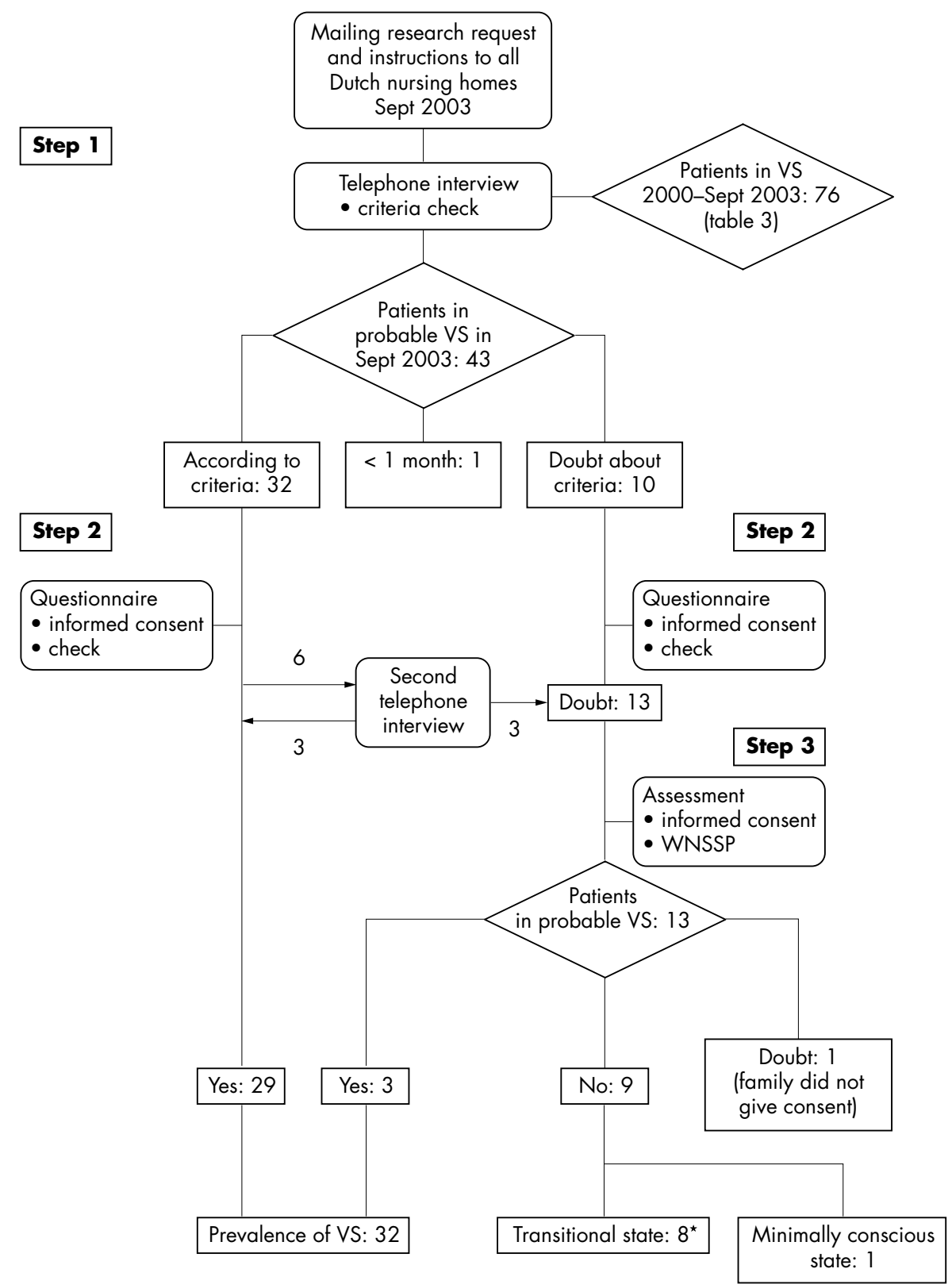

Figure 1 Flow chart of research design. *Criteria of "transitional state": sleep-wake pattern, being awake for a major part of the day; generally more definite localising to visual, auditory or tactile stimulation; tracking eye movements following objects or people; may show emotional responses to presence of family; may smile or cry. ${ }^{6}$

example, dementia) were excluded, since the diagnosis of vegetative state in Alzheimer disease has proved not to be easy and is subjective. ${ }^{21}$ Moreover, the characteristics of these patients and the medico-ethical dilemmas involved are different. During the telephone interview, the nursing home physicians were also asked to provide information on those patients in a vegetative state who were cared for between January 2000 and September 2003 and who had recovered and/or left the nursing home before 1 September 2003. We collected data on the end of the management of the episode of the vegetative state: recovery and/or discharge, death from comorbidity despite treatment, death from comorbidity after a non-treatment decision, or death from dehydration after withdrawal of $\mathrm{ANH}$. The nursing home physicians were asked to consult their medical records and colleagues and provided the information during the telephone interview or afterwards by email.
In step 2, for each of the patients probably in a vegetative state in September 2003, the nursing home physician directly responsible for the patient's care completed a questionnaire consisting of 10 items: sociodemographic data (date of birth, sex, marital status, place of residence before admission), medical history (date of brain accident, cause of brain accident, hospital diagnosis at discharge and manner of (tube) feeding), and consensus on the diagnosis with the multidisciplinary team and family, explained by no signs of consciousness, purposeful reactions or communication. There was one item on the direct effects of medication and metabolic disturbances on consciousness, which had to be ruled out. This item was in accordance with recent guidelines. ${ }^{8}$ The first author checked the clinical information in the collected questionnaires against diagnostic criteria for the vegetative state and sought clarification where needed. 
In step 3, in those instances where doubt about the diagnosis remained, the first author or two other experts assessed the patient. We chose the Western Neuro Sensory Stimulation Profile (WNSSP) as our structured assessment instrument..$^{22}$ The family and physician were invited to be present during the assessment. Information on the patient's functioning was obtained from family or caregivers and, when instructive, their interaction with the patient was observed. Afterwards, we provided feedback about the diagnosis to the physician and the family.

The questionnaire survey and all assessments were carried out with the written informed consent of the families concerned. The questionnaires were rendered anonymous. In five cases, the physician failed to return the questionnaire but responded after being sent a reminder. The family of one patient with doubts about the diagnosis did not consent to further investigation and this patient was therefore not included in the study.

We submitted the research protocol to the local research ethics committee for approval. However, according to the committee the study did not need ethical approval because it was not medical scientific research according to the criteria of the Dutch Medical Research Involving Human Subjects Act.

The results were statistically analysed using SPSS 11.0.

\section{RESULTS}

\section{Prevalence}

The results are shown in fig 1 . All the nursing homes in the Netherlands and the nursing home physicians participated in the study. Initially, we identified 43 possible patients in a vegetative state. One patient in a transfer unit of a nursing home in a hospital was excluded because the duration of vegetative state at the time of the study was less than one month.

After checking the questionnaires, the diagnosis was in accordance with the criteria in 29 patients but there was some doubt about the diagnosis in 13 patients. One patient could not be assessed because the family refused consent. In the remaining 12 patients, the diagnosis of vegetative state was confirmed in three patients, whereas eight were classified as being in a "transitional state", ${ }^{6}$ and in one patient a minimally conscious state was observed (in which the patient has the ability to follow simple commands).$^{24}$ This resulted in a total number of 32 patients in a vegetative state in nursing homes all over the Netherlands at the time of the study.

As the total number of nursing home beds in 2003 was 62331 , this resulted in a prevalence of 5.1/10 000 nursing home beds. For the Dutch population of 16.2 million, this means a prevalence of 2/1 000000 .

\section{Characteristics of the patients in a vegetative state}

The data of two of the 32 patients correctly diagnosed as in a vegetative state were not available as the families did not consent to the provision of data. Most patients (73.3\%) were female, and the mean age was 52.6 years (range 9-90; table 1). Six of the eight trauma patients were under 40 years.

The mean period of unconsciousness since the brain incident was six years, ranging from two months to 20.3 years. Most of the patients came from hospital, and stroke was the commonest cause of the vegetative state (14/30), particularly in patients older than $70(n=9)$. With the exception of one patient, all stroke patients were female.

For two trauma patients, the post-traumatic survival period was less than a year and for two stroke patients the survival period was less than six months after the event. The majority of patients $(n=26)$ had survived for more than a year: eight patients between five and 10 years and five more
Table 1 Main characteristics of patients in a vegetative state $(n=30,2$ missing)

\begin{tabular}{|c|c|}
\hline Age in years & $\begin{array}{l}\text { Mean } 52.6(22.2 \uparrow) \text {; median } 51.1 \\
\text { (range 9-90) }\end{array}$ \\
\hline $0-40^{*}$ & $11(36.7)$ \\
\hline $41-60 *$ & $7(23.3)$ \\
\hline $61-80 *$ & $8(26.7)$ \\
\hline$>80^{*}$ & $4(13.3)$ \\
\hline \multicolumn{2}{|l|}{ Sex distribution (male/female) } \\
\hline$<30$ & $2 / 3$ \\
\hline $30-39$ & $2 / 3$ \\
\hline $40-49$ & $1 / 4$ \\
\hline $50-59$ & $2 / 1$ \\
\hline $60-69$ & $0 / 3$ \\
\hline $70-79$ & $1 / 3$ \\
\hline $80-89$ & $0 / 4$ \\
\hline $90-99$ & $0 / 1$ \\
\hline Total & $8(26.7 \%) / 22(73.3 \%)$ \\
\hline \multicolumn{2}{|l|}{ Marital status } \\
\hline Not married* & $12(40.0)$ \\
\hline Married* & $12(40.0)$ \\
\hline Divorced* & $5(16.7)$ \\
\hline Widowed* & $1(3.3)$ \\
\hline \multicolumn{2}{|l|}{ Admitted from } \\
\hline Hospital $^{*}$ & $26(86.7)$ \\
\hline Rehabilitation centre* & $1(3.3)$ \\
\hline Home $^{*}$ & $2(6.7)$ \\
\hline Other nursing home* & $1(3.3)$ \\
\hline \multicolumn{2}{|l|}{ Cause of the vegetative state } \\
\hline Trauma* & $8(26.7)$ \\
\hline Stroke* & $14(46.7)$ \\
\hline Anoxia* & $7(23.3)$ \\
\hline Other* & $1(3.3)$ \\
\hline \multicolumn{2}{|l|}{ Duration of the vegetative state (months) } \\
\hline $0-6^{*}$ & $3(10.0)$ \\
\hline $6-12^{*}$ & $1(3.3)$ \\
\hline $12-60 *$ & $13(43.3)$ \\
\hline $60-120^{*}$ & $8(26.7)$ \\
\hline$>120^{*}$ & $5(16.7)$ \\
\hline For all patients $(n=30)$ & $\begin{array}{l}\text { Mean } 72.2(68.5 t) \text {; median } 50.7 \\
\text { (range 2.1-244.1) }\end{array}$ \\
\hline For patients aged $0-40(n=11)$ & $\begin{array}{l}\text { Mean } 90.1(77.7+) \text {; median } 91.8 \\
\text { (range 2.6-232) }\end{array}$ \\
\hline For patients over $70(n=10)$ & $\begin{array}{l}\text { Mean } 62.1(58.7+) \text {; median } 45.3 \\
\text { (range 2.1-187.2) }\end{array}$ \\
\hline \multicolumn{2}{|l|}{ Tube } \\
\hline $\begin{array}{l}\text { Percutaneous endoscopic } \\
\text { gastrostomy* }\end{array}$ & $24(80)$ \\
\hline Nasogastric* & 5 (16.7) \\
\hline No tube ${ }^{*}$ & $1(3.3)$ \\
\hline
\end{tabular}

than 10 years $(16.7 \%)$. This means that the prevalence of patients in a vegetative state for more than a year is 1.6 patients per million.

All but one patient received tube feeding. Five patients had a nasogastric tube (three having been in a vegetative state for more than five years and one for more than 16 years).

The results of the telephone survey of patients in a vegetative state between January 2000 and September 20003 are shown in fig 2. During that period, 43 patients died: 10 because of complications despite treatment, 24 because of complications after a non-treatment decision, and 9 after the withdrawal of ANH.

\section{DISCUSSION}

This is the first study on the prevalence of the vegetative state that covers a total population of nursing home patients. Most of the 32 patients had survived more than one year in a vegetative state and a substantial number even more than 10 years, which emphasises the long term care for this group of patients.

The strong points of our study include the participation of all nursing homes in the Netherlands and a full response 


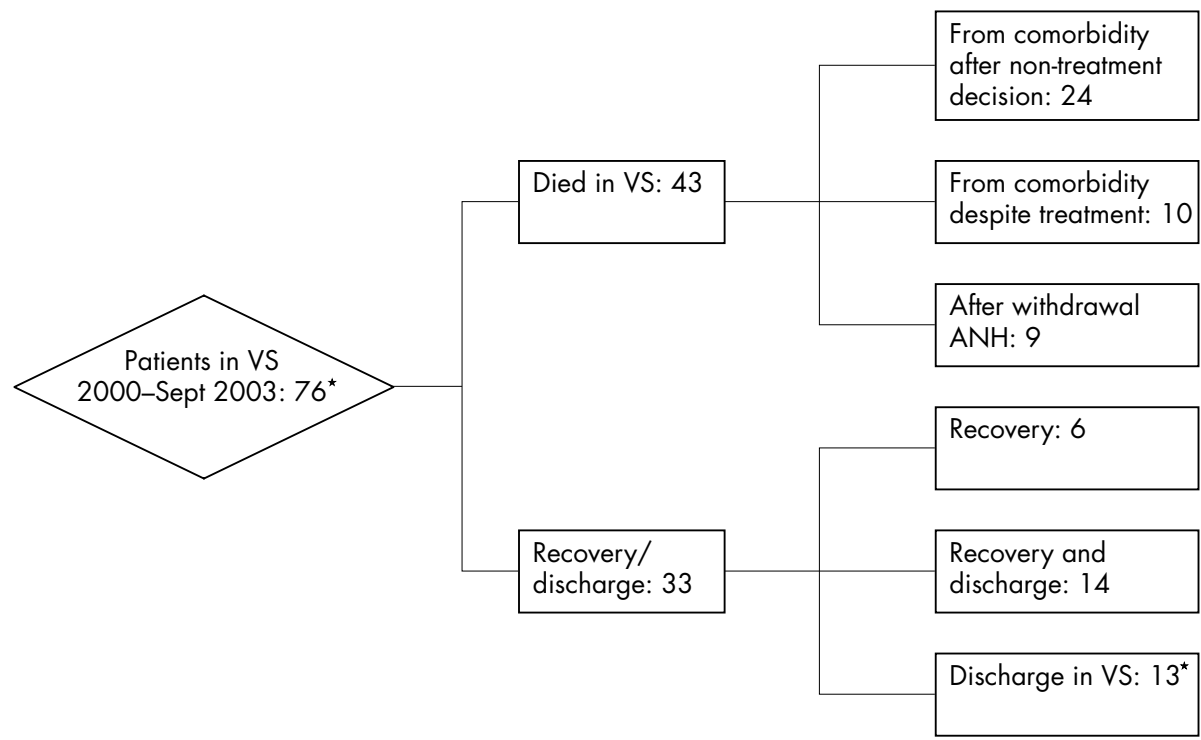

Figure 2 Patients in a vegetative state in Dutch nursing homes during 2000-September 2003. *One of the 13 patients was discharged to another country, 12 to other Dutch nursing homes. Three of these patients were known to have died in a nursing home after discharge. Without these double counts the total number of patients in a vegetative state was 73 . Double counts of other nine patients cannot be excluded from the total number.

from the nursing home physicians. Contrary to most other studies, we used uniform definitions, and strict inclusion criteria and assessment procedures based on updated international standards. ${ }^{419}$ Moreover, we involved the patients' families in the assessment when there was doubt. Thus, among 12 patients, we identified eight who did not respond to commands, but reacted emotionally to their family and/or could fixate on objects and follow them with their eyes. The International Working Party on the management of the vegetative state has discussed this category of patients but not reached consensus whether this stage should be considered vegetative or non-vegetative. ${ }^{6}$

In the Netherlands, patients in a vegetative state are admitted to nursing homes for long term care. Home care for these patients is exceptional. From this one may conclude that the prevalence of the vegetative state in the present study is low. There are only a few reports available for comparison. In 1991, approximately 3\% of the patients from four Milwaukee nursing homes were identified as being in a vegetative state. ${ }^{15}$ However, that study also included patients with dementia, and therefore the figures cannot be compared. A recent survey of 48 hospitals and 44 nursing facilities in Vienna showed a prevalence of 32 patients in a vegetative state, corresponding to a prevalence of 19 patients/ $1000000 .{ }^{13}$ That study of a local population with the same absolute number of patients in a vegetative state as was found in our study confirms that this number can be considered as low. Our findings are comparable with those of Minderhoud and Braakman, ${ }^{12}$ who reported 53 patients in a vegetative state for longer than six months in Dutch hospitals and nursing homes in 1983. However, in that study the response of nursing homes was low. In 1994, by extrapolation of data from a limited number of nursing homes, the Netherlands Health Council estimated the total number of patients in a vegetative state in the Dutch population to be between 100 and $200 .{ }^{9}$ The difference between that extrapolated prevalence and our findings may be explained by the different methods of establishing the prevalence (extrapolation $v$ real prevalence) and/or a change in medical decisions for these patients after 1994. Since that time, reports of the Health Council and the Royal Dutch Medical Association have concluded that it is justifiable to withdraw life sustaining treatment, including ANH, when the chance of recovery is negligible. ${ }^{9} 25$

However, there is no evidence that the low prevalence of vegetative state in this study reflects a policy of systematically withdrawing ANH. Firstly, our survey shows that a substantial proportion of the patients in a vegetative state were under care for more than five or even 10 years, which seems commoner than reported in previous studies. ${ }^{5} \mathrm{ANH}$ was apparently continued for these patients for all these years. Secondly, the retrospective part of our study (see fig 2) indicates that, in the three years before this study, only nine of 43 patients in a vegetative state had died due to the withdrawal of ANH. These data should be interpreted with caution, as the diagnosis of vegetative state had been established retrospectively. Nevertheless we think that the nine patients in whom ANH was withdrawn provide a realistic picture. The impact of the diagnosis vegetative state in relation to withdrawing ANH is high for everyone involved and we assume that the recollections of the nursing home physicians are reliable. Thus the withdrawal of ANH cannot account for the low prevalence and in our view comorbidity and not-treatment decisions for comorbidity (the common cause of death reported) seems to be a better explanation. This finding supports the view that physicians prefer to manage patients in a vegetative state by not treating lifethreatening comorbidity, rather than by withdrawing $\mathrm{ANH}^{26}$ Other explanations for the low prevalence include exclusion of dementia and a transitional state. The fact that we did not include hospitals and households could have resulted in an underestimation of the total prevalence in the Netherlands. It is likely that a number of patients were still in hospital prior to their transfer to a nursing home, although patients in transfer units of nursing homes in hospitals were included.

In our survey most patients in a vegetative state survived the crucial one year period after which recovery of consciousness is unlikely for all causes. ${ }^{5}$ There were only four patients for whom recovery could not be ruled out at the time of the study based on the prognostic crucial period of 12 months for traumatic vegetative state and six months for non-traumatic vegetative state. We recorded prolonged survival in elderly as well as in younger patients. The sex distribution in our study contrasts with the male 
preponderance reported in the Vienna survey. ${ }^{13}$ The fact that there were nearly three female for every male patient in our study is mainly because of the influence of status after stroke in our nursing home population. The average age of 52.6 years is young for a nursing home population. This perhaps indicates that the parents of patients in a vegetative state may be involved in decision making rather than children, as is usually the case in nursing homes. Virtually all patients received $\mathrm{ANH}$, as is known from other studies. ${ }^{15}$ The use of nasogastric tubes in current long term care is remarkable considering their complications. Recently, research into events and decision making in the long term care of such patients showed that withdrawal of ANH can be an acceptable scenario for letting the patient die, although this scenario cannot be applied in all situations. ${ }^{7}$

We have established accurately, for the first time, the prevalence of vegetative state in a nursing home population. We recommend that our survey be repeated to monitor developments in prevalence and to analyse factors which influence the figures. The use of uniform criteria is essential, and for that purpose we recommend classifying patients in a "transitional state" as not being in a vegetative state. The use of a standardised assessment instrument can be recommended to clarify such cases, although direct observation with participation of the family is important as well. Further research on this recently identifiable category is necessary because the medico-ethical implications differ for this group. ${ }^{27}$

We found a small group of patients in a vegetative state among the nursing home population and from a point of view of efficiency of care it may seem that concentration of care in a limited number of specialised nursing homes is to be recommended. However, we would strongly advise against such a development. It is known from literature that the bond between the family and the patient remains strong. ${ }^{28}$ This was something we also encountered in an earlier part of our study ${ }^{7}$ and care should include the fostering this relationship and not frustrating it by referring patients in a vegetative state to centres far away from their families. Provision of a central team of experts for questions and consultations with care providers may be an alternative to specialised centres.

The present study demonstrates that dedicated care for patients in a vegetative state may last for years and years. It is clear that every single case in this twilight zone between life and death will have immense impact on the families, carers, and society, despite the small numbers.

\section{ACKNOWLEDGEMENTS}

The authors thank all the nursing home physicians and families who participated in this study, and Hans Bor for his statistical support.

\section{Authors' affiliations \\ J C M Lavriisen, J S G van den Bosch, De Zorgboog, Bakel, the Netherlands \\ J C M Lavriisen, R T C M Koopmans, Department of Nursing Home Medicine, Radboud University Nijmegen Medical Centre, Nijmegen, the} Netherlands
C van Weel, Department of General Practice, Radboud University Nijmegen Medical Centre, Nijmegen, the Netherlands

Competing interests: none declared

\section{REFERENCES}

1 Jennett B, Plum F. Persistent vegetative state after brain damage. A syndrome in search of a name. Lancet 1972;1:734-7.

2 Freeman EA. The persistent vegetative state: a fate worse than death. Clin Rehabil 1992;6:159-65.

3 Jennett B. Vegetative state: causes, management, ethical dilemmas. Curr Anaesth Crit Care 1991;2:57-61.

4 The Multi-Society Task Force on PVS. Medical aspects of the persistent vegetative state (1). N Engl J Med 1994;330:1499-508.

5 The Multi-Society Task Force on PVS. Medical aspects of the persistent vegetative state (2). N Engl J Med 1994;330:1572-9.

6 Andrews K. International Working Party on the Management of the Vegetative State: summary report. Brain Inj 1996;10:797-806.

7 Lavrijsen J, Van den Bosch H, Koopmans R, et al. Events and decision-making in the long-term care of Dutch nursing home patients in a vegetative state. Brain Ini 2005; 19:67-75.

8 Royal College of Physicians Working Group. The vegetative state: guidance on diagnosis and management. Clin Med 2003;3:249-54.

9 Health Council of the Netherlands: Committee on Vegetative State. Patiënten in een vegetatieve toestand [Patients in a vegetative state]. The Hague: Health Council of the Netherlands, 1994.

10 Charatan F. Governor Jeb Bush intervenes in "right to die" case. BMJ 2003;327:949.

11 Jennett B. The vegetative state: medial facts, ethical and legal dilemmas. Cambridge: Cambridge University Press, 2002.

12 Minderhoud JM, Braakman R. Het vegeterende bestaan [The vegetative existence]. Ned Tijdschr Geneeskd 1985;129:2385-8.

13 Stepan C, Haidinger G, Binder H. Prevalence of persistent vegetative state/ apallic syndrome in Vienna. Eur J Neurol 2004;11:461-6.

14 Higashi K, Sakata Y, Hatano M, et al. Epidemiological studies on patients with a persistent vegetative state. J Neurol Neurosurg Psychiatry 1977;40:876-85.

15 Tresch DD, Sims FH, Duthie EH, et al. Clinical characteristics of patients in the persistent vegetative state. Arch Intern Med 1991;151:930-2.

16 Statistics Netherlands. www.cbs.nl, Voorburg/Heerlen: CBS 2003.

17 Hoek F, Penninx BWJH, Ligthart GJ, et al. Health care for older persons, a country profile: the Netherlands. J Am Geriatr Soc 2000;48:214-17.

18 Hoek JF, Ribbe MW, Hertogh CHPM, et al. The specialist training program for Nursing Home Physicians: a new professional challenge. J Am Med Dir Assoc 2001;2:326-30.

19 Lavrijsen JCM, Van den Bosch JSG, Costongs LGP, et al. Diagnostiek van vegetatieve toestand als basis voor medisch handelen op de grens van leven en dood [Diagnosis of vegetative state as a basis for medical treatment on the borderline between life and death]. Ned Tijdschr Geneeskd 2003;147:195-8.

20 Lavriisen JCM, Van den Bosch JSG. Medisch handelen bii patiënten in een chronisch coma; een bijdrage uit de verpleeghuisgeneeskunde [Medical treatment for patients in a vegetative state; a contribution of nursing home medicine]. Ned Tijdschr Geneeskd 1990;134:1529-32.

21 Volicer L, Berman SA, Cipolloni PB, et al. Persistent vegetative state in Alzheimer disease. Does it exist? Arch Neurol 1997;54:1382-4.

22 Ansell BJ, Keenan JE. The Western Neuro Sensory Stimulation Profile: a tool for assessing slow-to-recover head-injured patients. Arch Phys Med Rehabil 1989;70:104-8.

23 Ansell BJ, Keenan JE, de la Rocha O. Western Neuro Sensory Stimulation Profile. A tool for assessing slow-to-recover head-injured patients. Tustin, California: Western Neuro Care Center, 1989

24 Giacino JT, Ashwal S, Childs NL, et al. The minimally conscious state: definition and diagnostic criteria. Neurology 2002;58:349-53.

25 KNMG (Royal Dutch Medical Association) Commissie Aanvaardbaarheid Levensbeëindigend handelen. Medisch handelen rond het levenseinde bij wilsonbekwame patiënten [Medical end-of-life practice for incompetent patients: patients in a vegetative state]. Houten/Diegem: Bohn Stafleu Van Loghum, 1997.

26 Grubb A, Walsh P, Lambe N, et al. Survey of British clinicians' views on management of patients in persistent vegetative state. Lancet 1996;346:35-40

27 Cranford RE. The vegetative state and minimally conscious states: ethical implications. Geriatrics 1998;53:S70-S73.

28 Tresch D, Sims FH, Duthie EH Jr, Goldstein MD. Patients in a persistent vegetative state: attitudes and reactions of family members. J Am Geriatr Soc $1991 ; 39: 17-21$. 